\title{
ANALISIS PENGENDALIAN BIAYA PRODUKSI UNTUK MENILAI EFISIENSI DAN EFEKTIVITAS BIAYA PRODUKSI
}

\author{
Novela Irene Karly Massie ${ }^{1}$, David P.E Saerang ${ }^{2}$, Victorina Z. Tirayoh ${ }^{3}$ \\ 1,2,3 Jurusan Akuntansi, Fakultas Ekonomi dan Bisnis, Universitas Sam Ratulangi, J1. Kampus Bahu, Manado, \\ 95115, Indonesia \\ E-mail : novela.massie@gmail.com
}

\begin{abstract}
Company management is a series of actions undertaken by members of the organization in an effort to achieve organizational goals. Management has an important role in controlling production costs where the efficiency and effectiveness of production cost control is valued by cost centers ability to achieve expected production volume. The purpose of this research is to know how to control the production cost, to evaluate the efficiency of production cost at Pak Untung tofu factory at Teling Atas, Manado. The method used is qualitative descriptive. The result of this research shows that pak Untung tofu business has not done a good production cost control due to lack of cost planning that does not set the standard cost so that in a few months raw material purchase has increased the purchase price of raw materials.
\end{abstract}

Keywords : Control of production costs, efficiency, and effectiviness

\section{PENDAHULUAN}

Persaingan di era globalisasi saat ini sudah semakin kompetitif di antara para pelaku usaha yang ada, maka dari itu pihak manajemen pertanggung-jawaban mempunyai peran yang sangat penting dalam pencapaian tujuan, Manajemen berkemampuan untuk melihat kemungkinan dan kesempatan di masa yang akan datang. Manajemen perusahaan adalah merupakan serangkaian tindakan yang dilakukan oleh para anggota organisasi dalam upaya mencapai sasaran organisasi. Manajeman memiliki peran penting dalam hal pengendalian biaya produksi di mana efektifitas pengendalian biaya produksi di nilai atas kemampuan pusat biaya dalam mencapai volume produksi yang diharapkan pada tingkat kualitas tertentu. (Wilson, 2017). Pentingnya masalah biaya produksi dapat dijadikan sebagai alat pengendalian produksi, maka hal ini perlu diperhatikan oleh setiap pelaku usaha baik di usaha kecil, seperti "pabrik tahu pak untung". Mengingat bahwa banyaknya jenis usaha mikro, kecil, menengah (UMKM) sekarang ini yang menawarkan produk-produk bervariasi bahkan produk-produk baru dan unik.

Pengendalian biaya produksi ini, berfungsi untuk membandingkan biaya produksi yang sebenarnya dengan standar biaya produksi yang ditetapkan, Dengan adanya perbandingan tersebut dapat di Evaluasi apakah telah terjadi penyimpangan, baik penyimpangan yang merugikan dan penyimpangan yang menguntungkan. Proses produksi adalah suatu cara, metode, atau pun teknik menambah kegunaan suatu barang dan jasa dengan menggunakan faktor produksi yang ada, Proses produksi yang dilakukan oleh perusahaan dalam bidang manufaktur merupakan faktor penting karena berpengaruh terhadap biaya produksi perusahaan, baik persahaan yang berskala besar maupun perusahaan yang berskala kecil dan menengah (Jogjafilm, 2014). 


\section{TINJAUAN PUSTAKA}

\subsection{Konsep Dasar Akuntansi}

Konsep dasar akuntansi adalah hal-hal dasar membangun informasi akuntansi. Konsep dasar akuntansi saangat dibutuhkan untuk mempelajari bagaimana pengelolahan data keuangan dalam sebuah organisasi atau perusahaan. Dengan konsep dasar tersebut pengolahan data keuangan bisa di jamin berjalan dengan baik (Anugerah, 2015).

\subsection{Pengertian Akuntansi}

Akuntansi merupakan pencatatan transaksi keuangan secara sistematis pada suatu bisnis selama periode tertentu, yang dimaksudkan dengan transaksi disini ialah persetujuan antara dua pihak, di mana salah satu pihak menjual barang atau jasa, sedangkan pihak lain membeli barang atau jasa tersebut.

\subsection{Akuntansi Manajemen}

Secara spesifik peran akuntansi manajemen adalah :

1. Menyediakan informasi bagi manajer dalam menjalankan fungsi perencanaan, pengendalian, dan pengambilan keputusan.

2. Membantu manajer dalam mengarahkan dan mengendalikan operasi perusahaan.

3. Memotivasi manajer dan karyawan untuk bekerja sama untuk mencapai tujuan perusahaan.

\subsection{Pengertian Akuntansi Biaya}

Akuntansi Biaya adalah suatu bidang akuntansi yang diperuntukkan bagi proses pelacakan, pencatatan, dan analisis terhadap biaya-biaya yang berhubungan dengan aktivitas suatu organisasi untuk menghasilkan barang atau jasa. Sehubungan dengan ini maka para ahli mendefinisikan pengertian dan fungsi Akuntansi Biaya sebagai suatu prosedur untuk mencatat dan melaporkan hasil pengukuran dari biaya pembuatan barang dan jasa.

\subsection{Pengertian dan klasifikasi biaya}

\subsubsection{Pengertian biaya}

Pengertian biaya merupakan pengorbanan untuk memperoleh harta, sedangkan beban merupakan pengorbanan untuk memperoleh pendapatan. Semua aktivitas dapat di ukur dengan satuan uang yang lazim di sebut biaya dalam dunia bisnis.

\subsubsection{Objek biaya}

Objek biaya atau tujuan biaya (cost objective) adalah tempat di mana biaya atau aktivitas diakumulasikan atau di ukur. Unsur aktivitas yang dapat dijadikan sebagai objek biaya adalah :

1. Produk.

2. Produksi.

3. Departemen.

4. Divisi.

5. Lini produk.

\subsubsection{Klasifikasi biaya}

1. Produk.

Klasifikasi biaya yang umum digunakan adalah biaya dalam hubungan dengan :

2. Volume produksi.

3. Departemen dan pusat biaya.

4. Periode akuntansi.

5. Pengambilan keputusan.

\subsection{Pengendalian biaya produksi}

Pengendalian biaya di pandang sebagai usaha manajemen untuk mencapai sasaran biaya dalam kegiatan tertentu. Pengendalian biaya dapat dilakukan dengan berbagai cara, misalnya melalui program-program pengurangan biaya, perencanaan biaya, dan perhatian 
yang terus-menerus terhadap pengambilan keputusan biaya dalam kaitannya dengan pengeluaran biaya.

\subsection{Efisiensi}

Efisiensi merujuk pada sejumlah konsep yang terkait pada kegunaan pemaksimalan serta pemanfaatan seluruh sumber daya dalam proses produksi barang dan jasa.

\subsection{Perilaku biaya}

Perilaku biaya adalah pola perubahan biaya dalam kaitannya dengan perubahan volume kegiatan atau aktivitas yang dilakukan perusahaan, dengan kata lain perilaku biaya adalah istilah untuk menggambarkan apakah biaya berubah seiring dengan perubahan output. Besar-kecilnya biaya dapat di pengaruhi oleh volume produksi dan volume penjualan.

\section{METODE PENELITIAN}

\subsection{Jenis Penelitian}

Jenis penelitian yang digunakan adalah merupakan penelitian kualitatif deskriptif yaitu : penelitian kualitatif merupakan penelitian yang berhubungan dengan persepsi, dan pendapat dari orang, lembaga atau perusahaan yang di teliti.

\subsection{Tempat dan Waktu Penelitian}

Penelitian ini dilakukan pada pabrik tahu pak Untung, waktu penelitian dilaksanakan pada bulan Oktober 2017 - Februari 2018.

\subsection{Metode pengumpulan data}

\subsubsection{Jenis data}

Jenis data yang digunakan dalam penelitian ini adalah menggunakan jenis data kuantitatif yang berupa angka-angka yang bersifat statistik, yang didalamnya merupakan hasil laporan produksi perusahaan. Data ini di peroleh melalui suatu pengumpulan data dengan cara wawancara dan dokumentasi serta kemudian di analisis dengan proses lebih lanjut. Dalam penelitian ini penulis menggunakan data kuantitatif berupa : (a) data laporan produksi perusahaan tahun 2016; (b) data kapasitas produksi perusahaan.

\subsubsection{Sumber data}

Sumber data primer yang digunakan dalam penelitian ini berupa :

1. Catatan hasil wawancara seperti kapasitas produksi per hari.

2. Sejarah Perusahaan.

3. Struktur Organisasi.

4. Sumber data yang juga diperoleh dalam Data primer yaitu dengan melakukan Observasi atau pengamatan secara langsung pada objek penelitian dengan melihat bagaimana proses produksi yang dilakukan oleh pihak perusahaan.

5. Data Laporan Produksi

6. Data kuantitas Produksi

7. Data Sekunder berupa Literatur yang menunjang penelitian.

\subsubsection{Teknik pengumpulan data}

Data merupakan faktor penting dalam penelitian, untuk itu diperlukan teknik tertentu dalam pengumpulan data, teknik pengumpulan data yang digunakan dalam penelitian ini adalah sebagai berikut : (1) wawancara; dan (2) dokumentasi.

\subsection{Metode analisis}

Motode analisis yang digunakan dalam penelitian ini adalah metode kualitatif dengan pendekatan deskriptif dimana metode ini memandang objek sebagai suatu yang dinamis, hasil kunstruksi pemikiran dan interprestasi terhadap gejala yang di amati, serta utuh (Holistic) karena setiap aspek dari objek itu mempunyai satu kesatuan yang tidak dapat dipisahkan. 


\section{HASIL PENELITIAN DAN PEMBAHASAN}

\subsection{Hasil Penelitian}

1. Analisis selisih biaya bahan baku.

a. Evaluasi selisih harga bahan baku Dapat di hitung dengan menggunakan rumus perhitungan selisih harga bahan baku (SHB). Secara sistematik selisih harga bahan baku dapat dinyatakan dengan rumus sebagai berikut :

$$
\begin{aligned}
\mathrm{SHB} & =(\mathrm{HS} \times \mathrm{KS})-(\mathrm{HSt} \times \mathrm{KS}) \\
& =(\mathrm{HS}-\mathrm{HSt}) \times \mathrm{KS}
\end{aligned}
$$

b. Hasil perhitungan selisih kuantitas bahan baku dapat di hitung dengan melakukan Perhitungan selisih kuantitas bahan baku (SKB). Selisih kuantitas bahan baku dapat ditentukan dengan rumus sebagai berikut :

$$
\begin{aligned}
\mathrm{SKB} & =(\mathrm{KS} \times \mathrm{HSt})-(\mathrm{KSt} \times \mathrm{HSt}) \\
& =(\mathrm{KS}-\mathrm{KSt}) \times \mathrm{HSt}
\end{aligned}
$$

\begin{tabular}{|c|c|c|c|c|c|}
\hline \multirow[t]{2}{*}{ Bulan } & \multirow[t]{2}{*}{ Bahan baku } & \multicolumn{2}{|l|}{ Kuantitas } & \multirow[t]{2}{*}{ Harga Standar (Rp) } & \multirow[t]{2}{*}{ Selisih } \\
\hline & & Sesungguhnya & Standar & & \\
\hline Januari & Kedelei & $50 \mathrm{Kg}$ & $150 \mathrm{Kg}$ & $7.400,00$ & -740.000 \\
\hline Februari & Kedelei & $50 \mathrm{Kg}$ & $150 \mathrm{Kg}$ & $7.400,00$ & -740.000 \\
\hline Maret & Kedelei & $100 \mathrm{Kg}$ & $150 \mathrm{Kg}$ & $7.400,00$ & -370.000 \\
\hline April & Kedelei & $150 \mathrm{Kg}$ & $150 \mathrm{Kg}$ & $7.400,00$ & 0 \\
\hline Mei & Kedelei & $100 \mathrm{Kg}$ & $150 \mathrm{Kg}$ & $7.400,00$ & -370.000 \\
\hline Juni & Kedelei & $50 \mathrm{Kg}$ & $150 \mathrm{Kg}$ & $7.400,00$ & -740.000 \\
\hline \multirow[t]{2}{*}{ Bulan } & \multirow[t]{2}{*}{ Bahan baku } & Kuantitas & $(\mathbf{K g})$ & \multirow[t]{2}{*}{ Harga Standar (Rp) } & \multirow[t]{2}{*}{ Selisih } \\
\hline & & Sesungguhnya & Standar & & \\
\hline Juli & Kedelei & $50 \mathrm{Kg}$ & $150 \mathrm{Kg}$ & $7.400,00$ & -740.000 \\
\hline Agustus & Kedelei & $100 \mathrm{Kg}$ & $150 \mathrm{Kg}$ & $7.400,00$ & -370.000 \\
\hline September & Kedelei & $50 \mathrm{Kg}$ & $150 \mathrm{Kg}$ & $7.400,00$ & -740.000 \\
\hline Oktober & Kedelei & $100 \mathrm{Kg}$ & $150 \mathrm{Kg}$ & $7.400,00$ & -370.000 \\
\hline November & Kedelei & $150 \mathrm{Kg}$ & $150 \mathrm{Kg}$ & $7.400,00$ & 0 \\
\hline Desember & Kedelei & $100 \mathrm{Kg}$ & $150 \mathrm{Kg}$ & $7.400,00$ & -370.000 \\
\hline \multicolumn{5}{|l|}{ Total Selisih } & 5.550 .000 \\
\hline
\end{tabular}

Tabel 4.1

Hasil perhitungan selisih kuantitas bahan baku tahun 2016

Sumber : Pabrik tahu pak Untung, Data diolah

2. Analisis selisih biaya tenaga kerja.

a. Analisis selisih biaya tenaga kerja dapat di hitung dengan melakukan Perhitungan selisih tarif upah langsung (STU) dengan rumus sebagai berikut :

$$
\begin{aligned}
\text { STU } & =(\text { TS } \times \text { JS })-(\text { TSt } \times \text { JS }) \\
& =(\text { TS }- \text { TSt }) \times \text { JS }
\end{aligned}
$$

\section{Tabel 4.2}

Perhitungan selisih tarif upah tenaga kerja langsung tahun 2016

\begin{tabular}{|c|c|c|c|}
\hline $\begin{array}{c}\text { Tarif upah / } \\
\text { jam sesungguhnya } \\
(\text { Rp/Jam) }\end{array}$ & $\begin{array}{c}\text { Tarif upah / } \\
\text { jam standar } \\
\text { (Rp/Jam) }\end{array}$ & $\begin{array}{c}\text { Jam tenaga kerja } \\
\text { Sesungguhnya }\end{array}$ & $\begin{array}{c}\text { Selisih tarif } \\
\text { tenaga } \\
\text { kerja }\end{array}$ \\
\hline $7.500,00$ & $7.500,00$ & $7.200,00$ & 0 \\
\hline
\end{tabular}

Sumber : Pabrik tahu pak Untung, Data diolah 
b. Hasil Perhitungan selisih efisiensi upah tenaga kerja langsung dapat di hitung dengan melakukan perhitungan Selisih efisiensi upah langsung (SEUL) dan dapat dinyatakan dengan rumus sebagai berikut :

$$
\begin{aligned}
\text { SEUL } & =(\text { TSt } \times \text { JS })-(\text { TSt } \times \text { JSt }) \\
& =(\mathrm{JS}-\mathrm{JSt}) \times \mathrm{TSt}
\end{aligned}
$$

Tabel 4.3

Perhitungan selisih efisiensi upah tenaga kerja langsung tahun 2016

\begin{tabular}{|c|c|c|c|}
\hline $\begin{array}{c}\text { Jam Tenaga } \\
\text { Kerja } \\
\text { Sesungguhnya }\end{array}$ & $\begin{array}{c}\text { Jam Tenaga Kerja } \\
\text { Standar }\end{array}$ & $\begin{array}{c}\text { Tarif Upah / } \\
\text { Jam Standar } \\
\text { (Rp/Jam) }\end{array}$ & $\begin{array}{c}\text { Varians } \\
\text { Efisiensi }\end{array}$ \\
\hline $7.200,00$ & $7.200,00$ & $7.500,00$ & 0 \\
\hline
\end{tabular}

Sumber : Pabrik tahu pak Untung, Data diolah

3. Analisis selisish varians jam kerja biaya overhead pabrik.

a. Selisih varians jam kerja biaya overhead pabrik dapat di hitung menggunakan rumus sebagai berikut :

$$
\text { SJKBOP }=(\text { TStBOPV }- \text { TSBOPV }) \times \text { JKS }
$$

Tabel 4.4

Perhitungan selisih varians jam kerja biaya overhead pabrik tahun 2016

\begin{tabular}{|c|c|c|c|c|}
\hline $\begin{array}{c}\text { Kapasitas } \\
\text { Normal Produksi } \\
\begin{array}{c}\text { Untuk } \\
\text { Satu Tahun }\end{array}\end{array}$ & $\begin{array}{c}\text { Biaya } \\
\text { Overhead } \\
\text { Standar } \\
(\mathbf{R p})\end{array}$ & $\begin{array}{c}\text { Biaya } \\
\text { Overhead } \\
\text { Sesungguhnya } \\
(\mathbf{R p})\end{array}$ & $\begin{array}{c}\text { Jam } \\
\text { Kerja } \\
\text { Sesungguhnya }\end{array}$ & $\begin{array}{c}\text { Selisih } \\
(\mathbf{R p})\end{array}$ \\
\hline Pemeliharaan Mesin & $2.400 .000,00$ & $2.400 .000,00$ & $7.200,00$ & 0 \\
\hline Pemeliharaan Bangunan & $2.640 .000,00$ & $2.640 .000,00$ & $7.200,00$ & 0 \\
\hline Biaya Listrik dan Telepon & $3.300 .000,00$ & $1.000 .000,00$ & $7.200,00$ & 16.560 .000 .000 \\
\hline Biaya Pengiriman & $3.300 .000,00$ & $3.300 .000,00$ & $7.200,00$ & 0 \\
\hline Total & & & & 16.560 .000 .000 \\
\hline
\end{tabular}

Sumber : Pabrik tahu pak Untung, Data diolah

b. Selisih tarif overhead pabrik di hitung dengan menggunakan rumus sebagai berikut :

$$
\text { STOvP }=(\mathrm{JKSt}-\mathrm{JKS}) \times \mathrm{TStBOP}
$$

Tabel 4.5

Perhitungan selisih varians tarif overhead pabrik tahun 2016

\begin{tabular}{|c|c|c|c|c|}
\hline $\begin{array}{c}\text { Kapasitas Normal } \\
\text { Produksi } \\
\text { Untuk Satu Tahun }\end{array}$ & $\begin{array}{c}\text { Jam Kerja } \\
\text { Standar }\end{array}$ & $\begin{array}{c}\text { Jam Kerja } \\
\text { Sesungguhnya }\end{array}$ & $\begin{array}{c}\text { Biaya } \\
\text { Overhead } \\
\text { Standar } \\
(\text { Rp) }\end{array}$ & $\begin{array}{c}\text { Selisih } \\
\text { (Rp) }\end{array}$ \\
\hline Pemeliharaan Mesin & $7.200,00$ & $7.200,00$ & $2.400 .000,00$ & 0 \\
\hline Pemeliharaan Bangunan & $7.200,00$ & $7.200,00$ & $2.640 .000,00$ & 0 \\
\hline Biaya Listrik dan Telepon & $7.200,00$ & $7.200,00$ & $3.300 .000,00$ & 0 \\
\hline Biaya Pengiriman & $7.200,00$ & $7.200,00$ & $3.300 .000,00$ & 0 \\
\hline \multicolumn{4}{|l|}{ Total } & \multicolumn{3}{|l|}{} \\
\hline
\end{tabular}

Sumber : Pabrik tahu pak Untung, Data diolah 
4. Mengukur Efisiensi Biaya Produksi

Tabel 4.6

Mengukur Efisiensi Biaya Produksi

\begin{tabular}{|l|l|c|c|l|}
\hline Tahun & \multicolumn{1}{|c|}{ Periode } & Tingkat Efisiensi & Presentase & \multicolumn{1}{|c|}{ Keterangan } \\
\hline \multirow{7}{*}{2016} & 0,098 & $98 \%$ & Efisien \\
\cline { 2 - 5 } & Januari & 0,098 & $98 \%$ & Efisien \\
\cline { 2 - 5 } & Mebruari & 0,001 & $0,1 \%$ & Tidak efisien \\
\cline { 2 - 5 } & April & 0,986 & $98 \%$ & Efisien \\
\cline { 2 - 5 } & Mei & 0,986 & $98 \%$ & Efisien \\
\cline { 2 - 5 } & Juni & 1,351 & $1,351 \%$ & Sangat Efisien \\
\cline { 2 - 5 } & Juli & 1,351 & $1,351 \%$ & Sangat Efisien \\
\cline { 2 - 5 } & Agustus & 0,986 & $98 \%$ & Efisien \\
\cline { 2 - 5 } & September & 1,066 & $1,66 \%$ & Sangat Efisien \\
\cline { 2 - 5 } & Oktober & 0,986 & $98 \%$ & Efisien \\
\cline { 2 - 5 } & November & 0,986 & $98 \%$ & Efisien \\
\cline { 2 - 5 } & Desember & 0,986 & $98 \%$ & Efisien \\
\hline
\end{tabular}

Sumber : Pabrik tahu pak Untung, Data diolah

\subsection{Pembahasan}

1. Analisis selisih biaya bahan baku

Berdasarkan data harga standar bahan baku tahun 2016 perusahaan menetapkan standar harga bahan baku senilai Rp 7.500; per kilonya. Sesuai dengan perhitungan selisih harga bahan baku di ketahui terdapat selisih yang cukup menguntungkan yaitu sebesar Rp 210.000,00. Terjadinya selisih tersebut dikarenakan adanya pembelian bahan baku yang lebih rendah dari harga standar yang ditetakan oleh pihak perusahaan. Selanjutnya untuk perhitungan selisih kuantitas bahan baku diketahui bahwa terdapat selisih yang menguntungkan yaitu sebesar 5.550.000 karena kuantitas sesungguhnya bahan baku yang digunakan dalam proses produksi lebih kecil dari pada kuantitas produksi yang ditetapkan.

2. Berdasarkan data standar biaya tenaga kerja langsung Dalam penetapan standar tarif upah pihak manajemen menetapkan sebesar Rp 1.500.000,00 per bulan dan memberikan fasilitas lainnya yang menunjang. Perhitungan standar jam kerja untuk proses produksi ini adalah sebagai berikut :

1. Jumlah hari yang diperkirakan dalam satu bulan adalah 25 hari

2. Efektivita standar jam kerja perhari adalah 8 jam

3. Jumlah pekerja dalam sehari adalah 3 orang

4. Banyaknya jam kerja efektif dalam 1 tahun adalah: 3 orang x 8 jam per hari x 25 hari $\mathrm{x} 12$ bulan $=7,200$ jam

3. Berdasarkan data standar biaya overhead pabrik, terdapat Biaya Pemeliharaan mesin sebesar Rp Rp 2.400.000, Biaya pemeliharaan bangunan sebesar Rp 2.640.000, Biaya listrik dan telepon sebesar Rp 1.200.000, dan Biaya pengiriman sebesar Rp 3.300.000. Selisih menurut jam kerja diketahui bahwa pada tahun 2016 biaya overhead pabrik sesungguhnya lebih kecil dari pada biaya overhead pabrik standar pada kapasitas normal, sehingga terdapat selisih menguntungkan sebesar 16.560.000.000 (favoreble). Terlihat dari biaya overhead pabrik sesungguhnya dari biaya listrik dan telpon lebih kecil dari biaya listrik dan telpon yang distandarkan oleh perusahaan.

4. Mengukur Efisiensi Biaya Produksi.

Berdasarkan tabel tingkat efisiensi biaya produksi terdapat presentase yang berbedabeda terlihat pada bulan Juni, Juli, dan September memiliki presentase yang sangat efisien, dan di ikuti dengan presentase pada bulan Januari, Februari, April, Mei, 
Agustus, Oktober, November, dan Desember yang mengalami presentase efisien, dan terdapat presentase yang tidak efisien pada bulan maret.

\section{KESIMPULAN DAN SARAN}

\subsection{Kesimpulan}

Berdasarkan hasil penelitian dan pembahasan yang telah dikemukakan maka dapat di tarik kesimpulan bahwa:

1. Pabrik Tahu Pak Untung bergerak di bidang usaha Manufaktur yang merupakan bentuk usaha yang mengolah bahan mentah menjadi barang jadi, dalam hal ini usaha pak Untung memproduksi bahan pangan seperti Tahu. Dalam kegiatan produksinya perusahaan perlu memperhatikan pengendalian biaya produksi agar tetap bertahan dalam persaiangan industri yang sudah semakin ketat. Dari hasil penelitian yang dilakukan terlihat bahwa usaha Tahu pak Untung ini belumlah melakukan pengendalian biaya produksi yang baik, dikarekan terdapat perencanaan biaya yang tidak menetapkan standar biaya sehingga dalam beberapa bulan pembelian bahan baku mengalami peningkatan harga beli bahan baku.

2. Dari hasil penelitian yang dilakukan pada usaha Tahu pak Untung untuk hasil perhitungan selisih di ketahui bahwa harga bahan baku mengalami selisih yang cukup menguntungkan yaitu sebesar Rp 210.000,00. Begitu pun dengan perhitungan selisih kuantitas bahan baku juga mengalami selisih yang menguntungkan, Terjadinya selisih pada tahun tersebut dikarenakan bagian pembelian bahan baku, membeli bahan baku dengan harga yang lebih rendah dari harga standar yang ditetapkan yaitu pada bulan Januari, Februari, April, Mei, Agustur, Oktober, November, dan Desember. Dan pada perhitungan efisiensi upah langsung tidak terjadi selisih, karna perusahaan membayar tarif upah sesungguhnya sesuai dengan tarif upah standar langsung. Begitu pun dengan perhitungan selisih biaya overhead pabrik menurut tarif diketahui bahwa tidak terdapat selisih karena total selisih sama dengan nol. Standar yang telah ditetapkan ini hedaknya di tinjau secara periodik oleh pihak peusahaan agar standar yang di pakai sebagai alat untuk mengendalikan biaya akan tetap up to date.

3. Dalam penilaian tingkat efisiensi biaya produksi memiliki kriteria penilaian antara lain, presentase penilaian mulai dari $90 \%$ sampai dengan $>100 \%$ dikatakan Efisien - Sangat Efisien, sedangkan presentase mulai dari $80 \%$ sampai dengan $<60 \%$ dikatakan Kurang Efisien - Tidak Efisien. Dalam kasus ini pabrik tahu pak Untung tergolong kedalam kategori atau kriteria Efisien karena di lihat dari beberapa bulan selama tahun 2016 perusahaan melakukan kegiatan produksi dengan baik karena dari hasil penilaian presentase tergolong kedalam kriteria yang dikatakan Efisien.

\subsection{Saran}

Berdasarkan hasil penelitian yang telah di peroleh diharapkan dapat bermanfaat bagi perkemangan persahaan.

1. Standar sebagai alat pengendalian biaya hendaknya di tunjau setiap kali terjadinya fluktuasi harga, hal ini perlu dilakukan agar standar yang ditetapkan perusahaan telah di tinjau terlebih dahulu sesuai pertimbangan dari laporan terdahulu. Jadi, Perusahaan sebaiknya lebih meningkatkan sistem pengendalian saat berlangsungnya proses produksi agar tidak terjadi penyimpangan yang dapat merugikan perusahaan sehingga proses produksi bisa berjalan dengan efektif dan efisien.

2. Perusahaan sudah melakukan penetapan biaya standar dengan baik, akan tetapi untuk kedepannya diharapkan perusahaan bisa lebih memperhatikan harga bahan baku dan biaya overhead pabrik agar tidak terdapat selisih biaya yang kurang baik, hal ini dapat mempermudah perusahaan dalam melakukan analisis maupun evaluasi pada periode yang akan datang. 


\section{DAFTAR PUSTAKA}

Adityarafadhila 2015. Efektivitas pengendalian biaya produksi. https://www. kompasiana.com/adityarafadhia/efektivitas-pengendalian-biaya-produksi. $\quad 24$ Januari 2018.

2015.pengertian, unsur dan tujuan biaya produksi. https://www. kompasiana.com/dhanatsr/pengertian-unsur-dan-tujuan-biaya-produksi, diakses : Januari, 24, 2018.

Ahmad Maulidi, 2016. Pengertian data kuantitatif dan data kualitatif. https://www.kanalinfo.web.id/2016/03/pengertian-data-kuantitatif-dan data.html?m=1. 28 Juni 2018 (19:21). , dan Kamaruddin. 2013. Akuntansi Manajemen. Edisi Revisi, Cetakkan kedelapan. Raja Grafindo, Jakarta.

Anasthasia, 2016, Pengertian Struktur Organisasi. http://primanthaeveline.blogspot.co.id/2016/04/pengertian-struktur-organisasimenurut.html?m=1. 09 Oktober 2017.

Anthony , Hawkins, dan Merchant, 2016. delapan konsep dasar Akuntansi yang palingpenting.https://www.google.co.id/amp/s/dosenakuntansi.com/konsep-dasarakuntansi/amp. 24 Januari 2018.

Anugerah Dino, 2015.konsep dasar akuntansi. http://www.anugerahdino.com/2015/02/konsep-dasar-akuntansi.html?m=1. 26 Januari 2018.

Bustami dan Nurlela, 2013. Akuntansi biaya Edisi Empat. Jakarta : mitra wacana media.

Bastian bustami dan Nurlela, 2013. Bab 2landalsan teori. Klasifikasi biaya. https://library.binus.ac.id/eCaolls/eThesisdoc/bab2/RS1_2015_1_1064_bab2.pdf. 08 Mei 2017.

Carter dan Usry. 2017. Definisi, pengertian dan fungsi akuntansi biaya. https://id.m.wikipedia.org/wiki/Akuntansi_biaya. 21 Mei 2017.

, dan — 2015. Pengertian, fungsi, dan klasifikasi biaya. https://www.kembar.pro/2015/10/pengertian-fungsi-dan- klasifikasi-akuntansibiaya.html?m=1. 30 Januari 2018.

Chartered Institute of Management Accountants (CIMA), 2015. Pengertian, fungsi, tujuan, dan ruang lingkup akuntansi manajemen. https://www.kembar.pro/2015/05/pengertian-fungsi-tujuan-akuntansimanajemen.html?m=1. 30 Januari 2018.

Cornelisious, 2013. Indikator efisiensi dan teknik perhitungannya. https://www.google.co.id/amp/s/Cornelisious.wordpress.com/2013/04/18/indikatorefisiensi-dan-tekni-perhitungannya/amp/. 19 Februari 2018.

Diana khairani sofyan, 2013. perencanaan dan pengendalian produksi, Edisi pertama. yogyakarta : Graha ilmu.

Departemen Dalam Negeri, 1996. Keputusan Menteri Dalam Negeri. No.690.900-32 tentang Pedoman Penilaian Kinerja Keuangan PDAM. Sekretariat Negara, Jakarta.

Dedi Reiner, 2017. Pengertian dokumentasi menurut para ahli, fungsi, kegiatan, manfaat, pengkodean terlengkap. Http://www.spengetahuan.com/2017/09/pengertiandokumentasi-menurut-para-ahli-fungsi-kegiatan-manfaat-pengkodean.html. 30 juni 2018 (13: 46).

Emerson,2014.Pengertian efisiensi menurut para ahli. http://dilihatya.com/3209/pengertianefisiensi-menurut-para-ahli-adalah. 11 Mei 2017. 
F.Anggarsari, 2017.pengertian metode full costing. https//zahiraccounting.com/id/blog/fullcosting-dan-variabel-costing-apa-itu/. 30 Juni 2018 (12:34).

Ferry Rinaldi, 2015. Pengertian, fungsi, tujuan, dan ruang lingkup akuntansi manajemen. https://www.kembar.pro/2015/05/pengertian-fungsi-tujuan-akuntansimanajemen.html?m=1. 30 Januari 2018.

2015. Pengertian, fungsi, dan
https://www.kembar.pro/2015/10/pengertian-fungsi-dan-
biaya.html?m=1. 30 Januari 2018.

Glan A Welsch, 2017.pengertian dan fungsi anggaran menurut ahli. http://mangihot.blogspot.co.id/2017/02/pengertian-dan-fungsi-anggaranmenurut.html?m=1. 24 Januari 2018.

Halim, Supomo, \& Kusufi, 2013 : 21. Modul Akuntansi Manajemen-pengertian perilaku biaya.

http://mercubuana.ac.id/file/FakultasEkonomidanBisnis/Akuntansi.DedenTerminiAkuntansi-Manajemen/ModulAkuntansiManajemen. 01 Februari 2018.

dan Abdul. 2013. Akuntansi Manajemen. Edisi kedua. Penerbit BPFE, Yogyakarta.

Haidar server, 2017. Konsep dasar akuntansi (basic Accounting concept). https://haidarserver.blogspot.co.id/2017/02/konsep-dasar-akuntansi-basicaccounting.html?m=1. 26 Januari 2018.

Horngren, Datar, dan Rajan.2013.Cost Accounting:A Managerial Emphasis.Edisi Keempat Belas. Pearson Education Limited.Enggland.

Hadi mulyadi, 2013:27. Artikel pengertian Sistem Informasi Akuntansi Manajemen. https://repository.widyatama.ac.id/xmlui/bitstream/handle. 28 Juni 2018 (16: 57).

Kautsar.R.S, Mochammad farid, 2016. Akuntasi biaya pendekatan product costing, edisi kedua. Jakarta barat : indeks.

Kamaruddin 2013:148. Akuntansi Manajemen: Dasar-dasar konsep biaya dan pengambilan keputusan, Edisi Revisi 8. Jakarta : Rajawali Pers Bisnis.

Linda Agustina, analisis efisiensi objek wisata, pngertian efidiensi dalam teori ekonomi http://abstraksiekonomi.blogspot.com/2013/07/pengertian-efisiensi-dalam-teoriekonomi.html?m. 06 Juli 2017.

L.Suparwoto, 2017.pengertian akuntansi dan standar akuntansi pemerinta. https://www.google.id/amp/s/www.jurnal.id/blog/2017/pengertian-akuntansi-danstandar-akuntansi-pemerintah.amp\%3flocale=id. 26 Januari 2018.

Mahmet sahin Gok \& Erkut Altindag, 2015. Analysis of the cost and efficiency relationship : experience in the Turkish pay for performance system. The europian journal of health economics.

Michael, 2014. integrated evaluation of resource efficiency and cost effectiveness in production system.KTH Royal institute of technology school of industrial engineering and management department of production engineering.

Mulyadi, 2014. Bab2 landasan teori. Pengertian biaya. https:// library.binus.ac.id/eCaolls/eThesisdoc/bab2/RS1_2015_1_1064_bab2.pdf. 08 Mei 2017.

M. Mansouri Kaleibar, 2017. Cost, Revenue and Profit efficiency models in generalized Fuzzy data Envelopment Analysis. Fuzzy information. Engineering branch of the operations research society of china. (2017).

Paseban Agung, 2014. Artikel pengertian proses produksi. http://www.jogjafilm.com/id/article/read/pengertian-proses-produksi. 26 Januari 2018. 
Ran gao \& Beijin ye, 2014. The impact cost control on manufacturing industry profitability. School of civil engineering of norththeast forestry University, Harbin China. . Vol. 10 .

Rudianto, 2013. Akuntansi manajemen informasi untuk pengambilan keputusan strategis. Jakarta : Erlangga.

Rocket Manajemen, 2016.pengertian akuntansi secara umum dan jenis-jenisnya. http://rocketmanajemen.com/definisi-akuntansi/. 26 Januari 2018.

Samryn, 2012. Bab2 landasan teori. Pengertian biaya. https:// library.binus.ac.id/eCaolls/eThesisdoc/bab2/RS1_2015_1_1064_bab2.pdf. 08 Mei 2017.

Salman, dan Kautsar. 2013. Akuntansi Biaya Pendekatan Product Costing .Cetakan Pertama. Akademia Permata. Jakarta.

Schaum, 2017. Definisi, pengertian dan fungsi akuntansi biaya. https://id.m.wikipedia.org/wiki/Akuntansi_biaya. 21 Mei 2017.

Scribd, 2017. Perngertian pengendalian biaya produksi. https://www.scribd.com/mobile/doc/pengendalian-biaya-produksi. 30 Januari 2018.

- 2017. Pengertian biaya camuran atau biaya semi variable. http https://www.scribd.com/mobile/doc/biaya-campuran-atau-biaya-semi-variable. 01 Februari 2018.

Shevalina, 2013. Pengertian biaya variable. http//shevalina13.blogspot.com/2013/08/variable.costing.html?m=1. 30 Juni 2018 (12 :47).

Sianbola, 2017. The impact of cost control on manufacturing industries "profitability babcock University. Vol. 2.

Siregar, 2013. Akuntansi manajemen. Jakarta : Salemba Empat. , dkk, 2013. Akuntansi biaya Edisi kedua. Jakarta : Salemba Empat.

Simamora dan Henry. 2013. Akuntansi manajemen. Edisi III. Stard Date Publiser, Jakarta.

Suasanto, 2013. Pengertian efektifitas menrut para ahli. http://dilihatya.com/2664/pengertian-efektifitas-menurut-para-ahli-adalah\&ei=fSUnXBv\&lc=id-ID\&s=1\&m=13\&host. 06 Juli 2017.

Suryabrata, 2013 : 75. Pengertian deskriptif. Metodelogi penelitian bisnis cetakan ke-18. Bandung : Alfabeta.

Surjadi Lukman. 2013. Akuntansi Biaya. Dasar-dasar Perhitungan Harga Pokok. Cetakan Pertama. PT. Indeks. Jakarta.

Sujarweni V. Wiratna, 2015. Akuntansi Biaya teori dan penerapannya seluk beluk Akuntansi contoh dan aplikasi cetakan pertama. Yogyakarta : Pustaka Baru Press (PB).

Universitas ciputra, 2015. Biaya produksi dan cara menghitung biaya produksi.

Wikipedia,

Wilson, 2017. Pengertian manajemen perusahaan menurut para ahli lengkap. 